\title{
Medkulturnost v luči literarne vede
}

\author{
Krištof Jacek Kozak
}

\section{Izvleček}

Ugotovitev, da je človekova ustvarjalnost, kamor spada tudi književnost, brez meja, je postala že obče mesto. Ta članek se zato ne ukvarja s književnostjo per se, temveč z načini gledanja nanjo, kar pa je že samo po sebi odvisno od stanja v tisti družbi, v kateri je bila umetnost, ki jo proučujemo, tudi ustvarjena. Najbrž zato lahko trdimo, da je namen književnosti vselej presegati resničnost, ponuditi vedno pogled „preko“, kakršnega resničnost ne ponuja. Kako torej lahko z omejenimi sredstvi dojamemo neomejeno stvar? $\vee$ zadnjih dvesto letih so bile književnosti v narodnih jezikih razumljene kot nacionalne. Razprava o književnosti zato nujno zajame vprašanje nacije, s katero je bistveno povezano drugo vprašanje: kultura. Ali to pomeni, da je vprašanje nacionalne književnosti bolj politično kot estetsko in obratno? Videti je, da je ekskluzivna, eno-kulturna perspektiva za književnost škodljiva. Pričujoči prispevek se ukvarja s svetovno in primerjalno književnostjo ter njunimi več- in medkulturnimi perspektivami, kakor tudi razlikami v razmerju do samega pojma književnosti.

\section{Ključne besede}

nacionalna književnost; svetovna književnost; primerjalna književnost; večkulturna književnost; medkulturna književnost

\section{Abstract \\ Interculturality in Light of Literary Scholarship}

Realization that human artistic endeavours, where also literature belongs, have no borders has become a common place. This article will thus not deal with literature per se but with ways of looking at it, which, in their own turn, depend on the state of society the studied art was created in. It is probably safe to claim that the purpose of literature is always to transcend reality, to offer a look "across", which the reality does not offer. How then can we with limited means grasp un unlimited entity? For the last two hundred years literatures in vernacular languages have been understood as national. The discussion of literature necessarily spreads to the question of a nation and with the latter another issue is critically linked: the question of culture. Does that mean that the question of national literature is more political than aesthetic or vice versa? As it appears, an exclusive mono-cultural perspective would be detrimental to literature. This article deals with the concepts of world and comparative literatures and their multi- or intercultural perspectives and their own main idiosyncrasies in relation to the concept of literature.

\section{Key words}

national literature; world literature; comparative literature; multicultural literature; intercultural literature 


\section{Uvod}

Ugotovitev, da je človekova ustvarjalnost, kamor seveda spada tudi literatura, brez meja, neomejljiva, je postala že obče mesto. Kdo le bi lahko začrtal meje imaginaciji, ki, če si sposodimo primerjavo iz Nove zaveze, tako kot veter „veje, koder hoče, njegov glas slišiš, pa ne veš, od kod prihaja in kam gre“ (Jn 3, 8)? To velja tako za literarne notranje, popolnoma neodvisne kreativne pobude, kakor tudi za čisto konkretne zunanje vplive. Od vsega začetka je književnost - takrat še v svoji oralni obliki - služila ravno preseganju konkretne danosti in nagovarjanju transcendence, ki je bila človeku vselej fizično nedostopna, primerjanju in povezovanju svetov, ki se v resničnosti ne morejo srečati. Tako je že Gilgameš potoval po nasvet o nesmrtnosti k starcu Utnapištimu, ki mu je uspelo odkriti recept za večno življenje; drugi, manj pogumni, so v egipčanski (ali tibetanski) Knjigi mrtvih imeli vodnika, s katerim so lahko pričakovali mirno popotovanje na oni svet. Koliko vrlih junakov se je odpravljalo s Haronom čez Tartar, Stiks, ali Aheront, kradlo kot Prometej z Olimpa ali potovalo kot Orfej v Had? Koliko se jih je, tako rekoč božanskih ali polbožanskih, v Asiriji, Mezopotamiji, starem Egiptu in antični Grčiji v vzvišeni radosti združevalo z boginjami in bogovi? Koliko avtorjev se je, tako kot Dante, Milton ali Camões vračalo v te kronotope in jih oživljalo z novimi zgodbami? Koliko bralcev je trepetalo ob ljubezenskih zgodbah Dekamerona ali v Šeherezadinih brezkončnih nočeh?

Literatura, tako kot ideje, torej nima meja. Vplivanja njenih oseb, dogodkov in zgodb ne ustavljajo ne meje ne čas. Morda lahko tu in tam upadejo, se za hip umaknejo v ozadje, vendar kmalu spet oživijo z vso silo pristnih pripovedi. Na tem mestu pa trčimo ob jasen paradoks: naj bo literatura še tako neomejena, neposredna in trajna, jo njen (teoretični) razmislek obravnava lahko le na partikularen, omejen, „razkosan“ način, saj že v izhodišču podlega popolnoma drugačnim zakonitostim. Predvsem nima na voljo toliko kreativne svobode kot literatura, saj ga omejuje že predmet analize, pa tudi sam proces eksegeze se (običajno) dogaja s konceptualnim aparatom, ki ima svojo imanentno logiko, saj je sposojen od drugod. Književnost ostaja skozi stoletja pravzaprav nespremenjena, spreminjajo pa se naši pogledi nanjo, vprašanja, ki ji jih vedno znova zastavljamo, s tem pa tudi odgovori, ki jih od nje pričakujemo. Pravzaprav bi lahko celo ironično rekli, da nam razmislek o literaturi pove več o nas samih kot o predmetu analize, saj, če sledimo H. Saussyju, so vsa literarna dela med seboj že a priori povezana, vprašanje je le, kako. ${ }^{1}$

Pričujoči prispevek se zato ne bo ukvarjal s književnostjo, temveč načini in oblikami pogledov nanjo, ki pa so v največji meri odvisni od tistega stanja družbe, v katerem se proučevana literatura nahaja. Tako lahko ugotovimo, da se je sodobna analiza književnosti pričela v času romantike, ko je univerzalna književnost začela dobivati nacionalne obrise in so nacionalne meje začele omejevati tudi razmislek o literarnem ustvarjanju. Vendar je, kot se je izkazalo, slednji vselej skušal slediti imanentni naravi literature, presegati omejitve (nacionalne) realnosti ter ponujati modele za literarno ustvarjanje, ki so bili drugačni, predvsem pa širši od omejitev dejanskosti. Omenjeno velja za vse

1 SAUSSY, Haun: Exquisite Cadavers Stitched from Fresh Nightmares. In: SAUSSY, Haun (ur.): Comparative Literature in an Age of Globalization. Baltimore: Johns Hopkins University Press, 2004, s. 31. 
v pričujočem članku obravnavane koncepte: svetovne in primerjalne književnosti ter za multi- in medkulturni pogled na književnost. Z ozirom na to ugotovitev lahko najbrž sklenemo, da je namen književnosti vselej presegati resničnost, biti več(ja) od nje, ponujati tisti pogled onstran, ki nam ga dejanskost ne omogoča. Kako torej z omejenimi sredstvi zajeti nekaj neomejenega? Ker je bistvo človekove ustvarjalnosti in s tem tudi književnosti neomejeno, je videti pravi način vztrajnost in pravi pristop poskušanje, vselej pa se morata zavedati tiste druge razsežnosti onstran.

\section{O literarni umetnosti}

Do bistvene spremembe pri razmisleku o literaturi kot pojavu je prišlo relativno pozno. Analiza literature je nastala tako rekoč kot „stranski proizvod“ širšega procesa, ki se je utemeljil predvsem na oblikovanju sodobnega razumevanja identitete, do katerega pa je prišlo v romantiki, in sicer v Nemčiji. Romantični teoretiki so kot podlago oziroma sredstvo za posameznikovo identifikacijo, identifikacijo predvsem z etnijo (oziroma etnosom, če bi sledili predlogu I. Urbančiča $)^{2}$, narodom ali nacijo, določili jezik. ${ }^{3}$ Tako se je tudi, če ne predvsem, za literaturo izkazalo, da ima poleg estetske (poetične), o kateri je govoril že Aristotel, tudi politično (naciogeno) vlogo, se pravi, da je ključna pri vzpostavljanju narodne oziroma nacionalne (samo)zavesti. Še več, zanjo je celo bistvenega pomena. Zadnjih dvesto let torej literaturo, ki obstaja v posameznih jezikih in je podložna njihovim kodom, pojmujemo predvsem kot nacionalno, to pa zaradi tega, ker je jezik „vidni simbol etnične pripadnosti“, 4 slovnica, slovar in folklora pa „v romantičnem razumevanju edini pravi in neposredni izrazi nacionalne identitete “. ${ }^{5}$ Tako je literatura, pojmovana kot na primer nemška, poljska, portugalska, slovenska in angleška, postala ključni izraz nacionalnih monokultur. Nekoč „brezbrežna“ literatura se je tako ujela v (politični) ris nacionalnih jezikov in kultur, iz primeža katerega se vse do danes pravzaprav zaman skuša učinkovito izviti.

Če želimo torej govoriti o literaturi, tedaj ne moremo mimo vprašanja naroda/nacije. Očitno je tudi, da je z vprašanjem naroda in njegove literature avtomatično povezano tudi vprašanje kulture, kar pa obenem pomeni, da je vprašanje nacionalne literature prej politično kot pa estetsko. Ne glede na to je bistvo nacionalnega razumevanja kulture v tem, da se vzpostavi na podlagi drugačnosti od ostalih, da že implicitno vsebuje delitev na domačo in tujo, „našo in njihovo“. Gre za vzpostavljanje meja, ki pa vseeno niso, kakor opozarja Saussy, „zgolj arbitrarne črte, narisane na neprekinjeni pokrajini“.${ }^{6}$ Da to ni le

2 URBANČIČ, Ivan: Aporije teorije o etničnem in nacionalnem ter problem identitete. In: Migracijske teme. Zagreb: Institut za migracije i narodnosti, 1989, s. 167.

3 Sežet pregled razmerij med etnijo, jezikom in identiteto poda Marina Lukšič-Hacin v knjigi Multikulturalizem in migracije. Ljubljana: Založba ZRC, 1999, s. 44.

4 Ibidem, s. 52.

5 POGAČNIK, Jože: Književni susreti s drugima: jugoslavističke teme. Rijeka: Izdavački centar Rijeka, 1986, s. 164.

6 SAUSSY, Haun: Exquisite Cadavers Stitched from Fresh Nightmares. In: SAUSSY, Haun (ur.): Comparative Literature in an Age of Globalization. Baltimore: Johns Hopkins University Press, 2004, s. 17. 
teorija, dokazuje naš lasten, slovenski primer: Lukšič-Hacin navaja mnenji S. Južniča in R. Rizmana, ki zahodni različici formiranja naroda - ta temelji na ozemeljski konsolidaciji naroda in njegovih oblastnih struktur - dodata še srednjeevropsko, kjer se je narod „pojavil kot jezikovna in kulturna skupnost,“ ki se je uresničevala „ob podpori intelektualnih in kulturnih elit" ${ }^{7}$ Mnenju, da smo na primer Slovenci kot narod nastali v ontološkem okviru literature, ne oporeka več tako rekoč nihče.

Izključujoča monokulturna zavest bi bila seveda za literaturo pogubna. To velja že za družbo, glede katere M. Mesić pravi: „Čeprav kulturno različna družba ni v vsakem pogledu boljša, obstaja večja verjetnost, da bo dosegla boljše ravnovesje kvalitet, ki si jih dobra družba želi. " 8 Če je tako v družbenem okviru, še toliko bolj velja za umetnost in književnost. Medsebojni dialog različnih kultur je lahko le koristen, ker njihova homogenizacija nasprotno povzroča izgubo njihove različnosti. Zato je sama teorija pomembni odgovor, do katerega je prišlo tako rekoč hkrati s političnim oblikovanjem nacionalnih kultur/ literatur. Odtlej dalje poteka razmislek o književnosti vselej dvotirno: ob dominantnem, v družbi prevladujočem modelu je vselej zaslediti temu nasprotni pogled, ki, se zdi, skrbi za pravšnje ravnotežje, saj „kulturna različnost [...] ustvarja klimo za medsebojno koristen dialog raznovrstnih kultur, in to je to, kar delajo kreativni pisatelji in umetniki na sofisticiranem nivoju". 9

\subsection{Svetovna književnost}

Tako je tudi romantično razumevanje literature, ki izkazuje napor oblikovanja nacionalne identitete ter „skrb za afirmacijo nacionalne kulture“ ${ }^{10}$ že od vsega začetka spremljala nasprotna zavest, ki je razumela, da domače kulture in literature ne bi bilo brez tujih vplivov in se je zavedala, kako pomembno - tudi za razumevanje lastnega jaza - je preseganje obstoječih meja. Na tem mestu je treba omeniti dialoško definicijo sebstva, ki jo je uvedel francoski filozof E. Lévinas, in sicer da je definicija lastnega jaza mogoča le v dialogu z drugim. To pozicijo povzame tudi Mesić, ko pravi, da mi „definiramo svojo identiteto vedno $v$ dialogu $z$, ali včasih v boju proti"11 tistim elementom, ki jih drugi hočejo videti v nas. Zavedala se je, da je tudi univerzalizem, ki so ga predstavljale pretekle dobe, imel velik pomen za človekovo samospoznajo. Tako zavest je že v času romantike gojil J. W. von Goethe, sopotnik W. von Humboldta, J. G. Herderja, bratov A. W. in F. Schlegla, F. Schillerja in drugih, ki je na primer že kot ustvarjalec s svojim Zahodno-vzhodnim divanom opozarjal na prežemanje kultur, kot teoretik pa je povzel pojem, ki ga je sicer uvedel C. M. Wieland, ter tako v bistvu reagiral na nacionalno uokvirjanje literature. Gre za pojem svetovne književnosti oziroma Weltliteratur. Goethe je 31. 1. 1827 J. P. Eckermannu

7 LUKŠIČ-HACIN, Marina: Multikulturalizem in migracije. Ljubljana: Založba ZRC, 1999, s. 54.

8 MESIĆ, Milan: Multikulturalizam: društveni i teorijski izazovi. Zagreb: Školska knjiga, 2006, s. 103.

9 Ibidem, s. 102.

10 KOVAČ, Zvonko: Poredbena i/ili interkulturna povijest književnosti. Zagreb: Hrvatsko filološko društvo, 2001, s. 15 .

11 MESIĆ, Milan: Multikulturalizam: društveni i teorijski izazovi. Zagreb: Školska knjiga, 2006, s. 77. 
daljnovidno zaupal, da „nacionalna literatura zdaj ne pomeni veliko, čas je za dobo svetovne književnosti in vsakdo si mora prizadevati, da to dobo pospeši, "12 kajti poezija je "javno dobro človeštva in [...] se pousod in vedno pojavlja pri stotinah, resnično stotinah ljudi“. ${ }^{13}$ Do danes se teoretiki niso zedinili, na kakšen način naj bi natančno razumeli Goethejevo pripombo, čeprav se nagibajo k razlagi, ki jo ponuja tudi eno sodobnejših mnenj, ki pravi, da pri svetovni književnosti ne gre za vsoto vseh literarnih del, ki na svetu obstajajo, temveč za „način branja, ki ga lahko intenzivno izkusimo ob neštevilnih delih prav tako učinkovito kot ga lahko ekstenzivno raziskujemo ob velikem številu“. ${ }^{14}$ Koncept svetovne književnosti bi torej ne temeljil na nasilnem homogeniziranju kultur in literatur, temveč na prefinjenem vključevanju ustreznih del v svetovni kanon, na zavedanju, da znotraj kultur obstajajo različni kanoni, ki pa so pogosto lahko tudi nekompatibilni. ${ }^{15}$ Ko se je pojem literature „nacionaliziral“, je Weltliteratur poskrbela za „transnacionalno“ protiutež. Vendar pa je ostala zgolj to. Svetovna književnost je bila prva, ki je v svetu razlik odločno opozorila na kompatibilnost kultur in nujnost medsebojnega prehajanja vplivov, s čimer je postala pomemben vzor za kasnejše dobe.

\subsection{Primerjalna književnost}

Družbeni razvoj se je v 19. stoletju nadaljeval v smeri cepljenja človekovega vedenja. Velike nacije so se v tem času konsolidirale: v Evropi na primer združeni Nemčija in Italija. Nacionalnim vzpostavitvam so sledila tudi vsa druga področja človekovega teoretičnega delovanja in so - predvsem v 2. polovici 19. stoletja - doživela velik razmah. Poleg naravoslovnih so se začele osamosvajati in nastajati nove humanistične in družboslovne znanosti: lingvistika, antropologija, sociologija, religiologija... Predpostavka enotne in enovite človekove izkušnje sveta se je še bolj odmaknila, če ne celo zabrisala. In vendar je prav zaradi tega ta čas postregel s ponovnim poskusom preseganja svežih jarkov, izkopanih v celovitosti našega izkustva. Proti koncu 19. stoletja, potem ko so se, kot pravi D. Ferris, vzpostavile tradicionalne ločitve literarne vede, ${ }^{16}$ se je „izvila iz pene“ teorije nova humanistična veda: primerjalna književnost. Zagotovo je bil eden njenih idealov prav Goethejeva ideja svetovne književnosti, ${ }^{17}$ vendar so bili njeni cilji prilagojeni drugemu času: ni šlo več za združevanje vsega izkustva pod egido ene vede, enega načina razumevanja - kar je bil morda še Goethejev oddaljeni cilj -, pač pa je v razkosanem svetu, ki je postal že dejstvo, primerjalna književnost skušala presegati partikularnost človekove

12 ECKERMANN, Johann Peter: Goethes Gespräche mit Eckermann. Leipzig: Im Insel Verlag, 1928, s. 270.

13 Ibidem.

14 DAMrosCH, David: What is World Literature? Princeton: Princeton University Press, 2003, s. 299.

15 CAWS, Peter: Identity: Cultural, Transcultural, and Multicultural. In: GOLDBERG, David Thes (ur.): Multiculturalism. Cabridge: Blackwell, 1994, s. 374.

16 FERRIS, David: Indiscipline. In: SAUSSY, Haun (ur.): Comparative Literature in an Age of Globalization. Baltimore: Johns Hopkins University Press, 2004, s. 79.

17 BIRUS, Hendrik: The Goethean Concept of World Literature and Comparative Literature. In: CLCWeb: Comparative Literature and Culture, 2000, 2. 4. http://docs.lib.purdue.edu/clcweb/vol2/iss4/7. 
izkušnje. Poleg Goetheja vidi Saussy prekursorje primerjalne književnosti še v Mme de Staël, ki je po potovanjih v Nemčijo in na Avstrijsko 1810/13 objavila znamenito delo O Nemčiji (De l'Allemagne), s katerim je vpeljala kontrastivno metodo, ter v Madžaru iz Transilvanije, Hugu Meltzlu de Lomnitzu, ki je 1877 ustanovil časopis Primerjalna akta svetovnih književnosti (Acta comparationis literarum universarium) itd.

Vseeno pa se je morala, ne glede na to, da je imela primerjalna književnost za svoje izhodišče „univerzalnost človeške izkušnje“ ${ }^{18}$ že na začetku spopadati z nerazumevanjem. Novoustanovljene nacionalne literarne vede so jo namreč zavračale, češ da je preveč kozmopolitska in s tem oddaljena od prave snovi preučevanja. Kljub začetnemu odporu se je primerjalna književnost vztrajno razvijala in dosegla tudi svoj veliki uspeh (predvsem v 2. polovici 20. stoletja z razvojem literarnih teorij), ki pa je, kot vsak vrh, obenem pomenil tudi začetek njenega če ne razkroja, pa vsaj izrazitega krčenja. Prva je namreč ponudila na teoriji - tudi klasični, kontinentalni filozofiji - utemeljeno analizo literature. ${ }^{19}$ Nacionalne literarne vede so seveda pospešeno sprejele njeno metodo, ki jo Saussy vidi kot komparativistični refleks oziroma način mišljenja, ${ }^{20} \mathrm{~s}$ tem pa tudi poskrbele za zlitje metod. Tako so dosegle, da se primerjalna književnost od njih ni po ničemer več razlikovala. To ni tako nepomembno: če je namreč literatura en sistem, potem je lahko razmislek o njej, pravijo komparativisti, samo primerjalen, saj vzpostavlja razmerja med deli tega sistema. Ravno zato, ker so v literaturi kulture in jeziki neprestano v stiku, prihaja do hibridizacije oblik in mešanja vplivov (eden takih primerov v sodobnem svetu je opus nobelovke E. Jelinek, sicer pa na primer konkretna poezija itd.). Logika primerjalne književnosti je pravzaprav tako stara kot književnost sama.

Toda prav v tem je tudi problem. Z ozirom na to, da je „,transnacionalna“ dimenzija literature in kulture univerzalno priznana“, ${ }^{21}$ sta se, kot pravi Ferris, v primerjalni književnosti spopadla dva tokova - z ene strani težnja po vzpostavitvi vede, zaradi česar je, kakor naprej opozarja Saussy, nagnjena k „raztapljanju identitet [...], njihovih posamičnih ekspresij v skupni izvor",22 z druge pa tej prav nasprotna želja po prehajanju (primerjanju) brez meja (tu Ferris navaja mnenje F. Schillerja, ki je že vedel, da je svet načeloma fragmentarizirana izkušnja). ${ }^{23}$ Zaradi tega je primerjalni književnosti umanjkalo pravzaprav njeno bistvo: lastna metoda, differentia specifica, zaradi česar se ni mogla več vzpostaviti kot izrazito in razločno polje, ${ }^{24}$ oziroma drugače: bila je tako uspešna in učinkovita, da „smo

18 SAUSSY, Haun: Exquisite Cadavers Stitched from Fresh Nightmares. In: SAUSSY, Haun (ur.): Comparative Literature in an Age of Globalization. Baltimore: Johns Hopkins University Press, 2004, s. 13.

19 O tem pišeta dva pregleda stanja vede, ki ju je izdala Ameriška zveza za primerjalno književnost, in sicer Primerjalna književnost v dobi multikulturalizma (Comparative Literature in the Age of Multiculturalism), ur. Charles Bernheimer, 1993, ter Primerjalna književnost $v$ dobi globalizacije (Comparative Literature in an Age of Globalization), ur. Haun Saussy, 2004).

20 SAUSSY, Haun: Exquisite Cadavers Stitched from Fresh Nightmares. In: SAUSSY, Haun (ur.): Comparative Literature in an Age of Globalization. Baltimore: Johns Hopkins University Press, 2004, s. 5.

21 Ibidem, s. 3.

22 Ibidem, s. 7.

23 FERRIS, David: Indiscipline. In: SAUSSY, Haun (ur.): Comparative Literature in an Age of Globalization. Baltimore: Johns Hopkins University Press, 2004, s. 84.

24 Ibidem, s. 85; CULLER, Jonathan: Comparative Literature, at Last. In: SAUSSY, Haun (ur.): Comparative 
vsi [postali] komparativisti“, ${ }^{25}$ kar bi ne bilo še tako slabo za primerjalno književnost, če bi do tega seveda ne prišlo na „najnižjem skupnem imenovalcu“.${ }^{26}$ Teorijo so „obvladale“ tudi že nacionalne literarne vede, tako da ima primerjalna književnost že nekaj časa težave $\mathrm{z}$ identiteto, pa tudi z vizijo svoje prihodnosti. Posledica tega procesa je zapis francoskega filozofa A. Badiouja, ki je v Malem priročniku inestetike zabeležil, da „ne verjame [...] preveč v primerjalno književnost ". ${ }^{27}$ Kot opombo ob rob lahko zapišemo, da primerjalno književnost v današnjem času dejansko izrivajo tudi iz univerz: leta 2003 so zaprli oddelek za primerjalno književnost $\mathrm{z}$ več kot štiridesetletno tradicijo na Univerzi v Alberti v Kanadi, leta 2010 pa je enaka usoda doletela še komparativistični oddelek na Univerzi v Torontu, prav tako v Kanadi, ki ga je 1969 ustanovil N. Frye in na katerem so predavala taka imena kot, denimo, L. Doležel, E. Kushner in L. Hutcheon. ${ }^{28}$ Primerjalni književnosti, ki predstavlja prvi resni poskus preseganja vzpostavljenih nacionalnih meja, lahko bi rekli celo medkulturni pogled, je bila odvzeta prav njena funkcija „pogleda preko“, s tem pa tudi - tako sodi večina „nacionalnih“ teoretikov književnosti - raison d'être za obstoj. Ne glede na to, vprašanje, ali danes svet, ki se globalizira, ponuja drugačen, predvsem pa bolj poglobljen uvid v vprašanje kultur, ostaja.

Z resnično univerzalno širitvijo polja so v delavnico primerjalne književnosti vstopile tudi ameriške, azijske, afriške idr. književnosti, s čimer si pa tradicionalna veda ni znala prav veliko pomagati. Zaradi tega je bila primerjalna književnost hitro deležna očitkov glede evrocentričnosti. ${ }^{29}$ Če so bili komparativisti „navdušeni nad neukrotljivo raznolikostjo Babilona“, ${ }^{30}$ se je potem začelo vedno jasneje kazati, da je še tako velika raznolikost vendarle omejena. Dejanska tla pod nogami so primerjalni književnosti spodmaknili drugi svetovni procesi, ki so omogočili nastanek novih ved in novih pogledov - tudi na književnost. Eni zato vidijo možnosti primerjalne književnosti v razvoju v kulturne študije (S. Tötösy de Zepetnek; pri tem mu - iz popolnoma drugega izhodišča - sekundira Saussy z mnenjem, da so kulturni študiji zares komparativni kulturni študiji), ${ }^{31}$ drugi razmišljajo o koncu vede (G. C. Spivak v svoji knjigi Smrt vede (Death of a Discipline)),

Literature in an Age of Globalization. Baltimore: Johns Hopkins University Press, 2004, s. 238.

25 SAUSSY, Haun: Exquisite Cadavers Stitched from Fresh Nightmares. In: SAUSSY, Haun (ur.): Comparative Literature in an Age of Globalization. Baltimore: Johns Hopkins University Press, 2004, s. 4.

26 Ibidem.

27 APTER, Emily: Je ne crois pas beaucoup à la littérature comparée: Universal Poetics and Postcolonial Comparatism. In: SAUSSY, Haun (ur.): Comparative Literature in an Age of Globalization. Baltimore: Johns Hopkins University Press, 2004, s. 54.

28 Linda Hutcheon je, takoj za N. Fryjem in Ch. Taylorjem, eno bolj prepoznavnih imen kanadske literarne vede. Posebej se je specializirala za postmodernistično kulturo in kritično teorijo. Eva Kushner, prav tako Kanadčanka, se ukvarja predvsem s teorijo primerjalne književnosti in literarne zgodovine, medtem ko je Lubomir Doležel, po poreklu Čeh, leta 1968 zapustil domovino in bil povabljen na Univerzo v Torontu. Kot jezikoslovec je bil pod vplivom analitične filozofije, posebej še teorije možnih svetov.

29 HUTCHEON, Linda: Comparative Literature: Congenitally Contrarian. In: SAUSSY, Haun (ur.): Comparative Literature in an Age of Globalization. Baltimore: Johns Hopkins University Press, 2004, s. 225.

30 STEINER, George: What is Comparative Literature? In: STEINER, George: An Inaugural Lecture Delivered Before the University of Oxford. Oxford: Clarendon Press, 1995, s. 7.

31 SAUSSY, Haun: Exquisite Cadavers Stitched from Fresh Nightmares. In: SAUSSY, Haun (ur.): Comparative Literature in an Age of Globalization. Baltimore: Johns Hopkins University Press, 2004, s. 20. 
medtem ko tretji predlagajo dialektični povratek primerjalne književnosti k pojmu svetovne književnosti (D. Damrosch v knjigi Kaj je svetouna knjižeunost? (What is World Literature?)). Ponovno se lahko vprašamo, ali je univerzalno, prav tisto, od katerega so se začele odklanjati nacionalne literature, sploh še mogoče?

\subsection{Multikulturnost}

Vprašanje ima toliko večjo težo, ker se je svet znašel v primežu dveh nasprotujočih si procesov. Z ene strani se je začel na področju družbenih znanosti in humanistike, pod vplivom teoretičnih usmeritev kot sta postmodernizem in dekonstrukcija, razkrajati. Propadal je svet, ki se je vzpostavil na podlagi nacionalnega, zato tudi reificirani svet, ki ga je zanimala predvsem realnost. Proces devolucije pa je ponudil novo razumevanje sveta, sveta Baudrillardovega simulakra, za katerega je značilen predvsem razkroj absoluta, propad dotlej nedotakljivih vrednot. $\mathrm{S}$ tem se je iztekel tudi rok pojmovanju naroda in nacije kot večne in nespremenljive kategorije. Namesto tega smo ugotovili, kako porozna so vsa absolutizirajoča določila, kako izmuzljivi so pojmi kot sta narod in nacija, kako vprašljiv je pojem enovite identitete... Z druge strani pa se je ravno tak, razkrajajoči se svet na ekonomskem in političnem področju začel spet sestavljati in združevati. Gre seveda za procese (predvsem, a ne zgolj, ekonomske) globalizacije, ki se jim je v zadnjem času precej pospešeno pridružilo tudi politično združevanje (na primer širitev Evropske unije). Jasno je tudi, da v primeru globalizacije ne gre za vračanje v pred-dekonstrukcijsko realnost, $\mathrm{v}$ čas enotnih nacionalnih in individualnih identitet, ki je minil.

Hkrati z globalizacijo in kot odgovor nanjo je v družbenih vedah in humanistiki znova oživela teorija multikulturnosti, saj, kakor opozarja Rizman, globalizacija sproža fragmentarizacijo. ${ }^{32}$ Da gre za zapleten in v samem sebi protisloven pojem je obširno utemeljil Mesić v knjigi Multikulturalizem. Predvsem (̌̌e) ni popolnoma jasno in dokončno določeno, kakšne konotacije pojem vsebuje, saj je njegov pomen malodane odvisen od kulture, $\mathrm{v}$ kateri nastopa. Multikulturalizem je na primer tudi uradna politika Kanade, zato ima tu še nekoliko drugačen pomen kot drugje. Prav Mesić se ukvarja še z različnimi drugimi določili tega termina. ${ }^{33}$ Zagotovo velja, da obstajajo njene navzkrižne definicije med politično, sociološko, ekonomsko ali antropološko uporabo. Mesič zagovarja razlikovanje med multikulturnostjo in medkulturnostjo na podlagi njunega razumevanja kulture, saj multikulturnost zgolj ugotavlja pluralizem kultur. ${ }^{34} \mathrm{~V}$ tem lahko hitro zapade $\mathrm{v}$ „esencialistično podporo kulturni zaprtosti“ “. ${ }^{55}$ To je pojem, ki ima praktične posledice za organizacijo družbenega življenja, zato so medsebojna razmerja, ki jih vzpostavlja, toliko bolj zapletena.

32 RIZMAN, Rudi: Globalizacija in avtonomija: prispevki za sociologijo globalizacije. Ljubljana: Znanstvena založba Filozofske fakultete, 2008, s. 14.

33 MESIĆ, Milan: Multikulturalizam: društveni i teorijski izazovi. Zagreb: Školska knjiga, 2006, s. 55 in dalje.

34 Ibidem, 2006, s. 66-67.

35 Ibidem. 


\section{Bibliografija}

APTER, E.: Je ne crois pas beaucoup à la littérature comparée: Universal Poetics and Postcolonial Comparatism. In: SAUSSY, H. (ur.): Comparative Literature in an Age of Globalization. Baltimore: Johns Hopkins University Press, 2004, s. 54-62.

BERNHEIMER, Ch. (ur.): Comparative literature in the Age of Multiculturalism. Baltimore - London: Johns Hopkins University Press, 1995.

BIRUS, H.: The Goethean Concept of World Literature and Comparative Literature. In: CLCWeb: Comparative Literature and Culture, 2000, 2. 4. http://docs.lib.purdue.edu/clcweb/vol2/iss4/7.

BOUTON, M.: Medkulturni Management. In: MIKOLIČ, V. - KOZAK, K. J. (ur.): Medkulturni dialog kot temeljna vrednota EU. Koper: Annales, 2008, s. 133-138.

CAWS, P.: Identity: Cultural, Transcultural, and Multicultural. In: GOLDBERG, D. T. (ur.): Multiculturalism. Cabridge: Blackwell, 1994.

CULLER, J.: Comparative Literature, at Last. In: SAUSSY, H. (ur.): Comparative Literature in an Age of globalization. Baltimore: Johns Hopkins University Press, 2004, s. 237-248.

DAMROSCH, D.: What is World Literature? Princeton: Princeton University Press, 2003.

DAMROSCH, D.: World Literature in a Postcanonical, Hypercanonical Age. In: SAUSSY, H. (ur.): Comparative Literature in an Age of globalization. Baltimore: Johns Hopkins University Press, 2004, s. 43-53.

ECKERMANN, J. P.: Goethes Gespräche mit Eckermann. Leipzig: Im Insel Verlagti. Koper: Annales, 2009, s. 13-35.

SPIVAK, G. C.: Death of a discipline. New York: Columbia University Press, 2003.

STEINER, G.: What is Comparative Literature? In: STEINER, G.: An Inaugural Lecture Delivered Before the University of Oxford. Oxford: Clarendon Press, 1995.

Svetovne književnosti in obrobja. Ur. Marko Juvan. Ljubljana: Založba ZRC, ZRC SAZU, 2012.

TÖTÖSY DE ZEPETNEK, S.: From Comparative Literature Today toward Comparative Cultural Studies. In: CLCWeb: Comparative Literature and Culture, 1999, 1. 3. http://docs.lib.purdue.edu/ clcweb/vol1/iss3/2.

URBANČIČ, I.: Aporije teorije o etničnem in nacionalnem ter problem identitete. In: Migracijske teme. Zagreb: Institut za migracije i narodnosti, 1989, 2-3.

VIRK, T.: Primerjalna književnost na prelomu tisočletja. Kritični pregled. Ljubljana: Založba ZRC, ZRC SAZU, 2007.

ECKERMANN, J. P.: Goethes Gespräche mit Eckermann. Leipzig: Im Insel Verlagti. Koper: Annales, 2009, s. 13-35.

SPIVAK, G. C.: Death of a discipline. New York: Columbia University Press, 2003.

STEINER, G.: What is Comparative Literature? In: STEINER, G.: An Inaugural Lecture Delivered Before the University of Oxford. Oxford: Clarendon Press, 1995.

Svetovne književnosti in obrobja. Ur. Marko Juvan. Ljubljana: Založba ZRC, ZRC SAZU, 2012.

TÖTÖSY DE ZEPETNEK, S.: From Comparative Literature Today toward Comparative Cultural Studies. In: CLCWeb: Comparative Literature and Culture, 1999, 1. 3. http://docs.lib.purdue.edu/ clcweb/vol1/iss3/2.

URBANČIČ, I.: Aporije teorije o etničnem in nacionalnem ter problem identitete. In: Migracijske teme. Zagreb: Institut za migracije i narodnosti, 1989, 2-3. 
VIRK, T.: Primerjalna knjižeunost na prelomu tisočletja. Kritični pregled. Ljubljana: Založba ZRC, ZRC SAZU, 2007.

\section{red. prof. dr. Krištof Jacek Kozak}

Oddelek za slovenistiko

Univerza na Primorskem, Fakulteta za humanistične študije

Titov trg 5, Koper 6000, Slovenija

kjkozak@fhs.upr.si 